\title{
Predictors of Biochemical Failure Following Radical Prostatectomy With Positive Surgical Margins
}

\author{
Bahram Mofid, ${ }^{1}$ Ali Kakroodi, ${ }^{2}$ Nasser Simforoosh, ${ }^{3}$ Afshin Rakhsha, ${ }^{1}$ and Ahmad R. \\ Mafi $^{4, *}$ \\ 'Shohada Hospital, Shahid Beheshti University of Medical Sciences, Tehran, IR Iran \\ 'Shahid Rajaee Hospital, Babolsar, IR Iran \\ 3Labbafinejad Hospital, Shahid Beheshti University of Medical Sciences, Tehran, IR Iran \\ ${ }^{4}$ Imam Hossein Hospital, Shahid Beheshti University of Medical Sciences, Tehran, IR Iran \\ *Corresponding author: Ahmad R. Mafi, Imam Hossein Hospital, Shahid Beheshti University of Medical Sciences, Tehran, IR Iran. Tel: +98-9127796354, Fax: \\ +98-2122231034, E-mail:ahmadrmafi@yahoo.com \\ Received: March 11, 2015; Revised: April 4, 2015; Accepted: May 27, 2015
}

\begin{abstract}
Background: Radical prostatectomy is an established treatment modality for prostate cancer. Following radical prostatectomy, patients with positive surgical margins have increased risk of biochemical, and subsequently, clinical relapse. However, not all patients with positive margins will suffer disease recurrence. The aim of this study was to assess the factors that might predict the higher risk of disease recurrence in prostate cancer patients with positive surgical margins.

Objectives: The aim of this study was to assess the factors that might predict the higher risk of disease recurrence in prostate cancer patients with positive surgical margins.

Patients and Methods: From March 2009 till October 2013, seventy seven patients who had pathologically proven positive surgical margins after radical prostatectomy were followed and serum PSA levels were measured every three months. In case of biochemical failure, they were treated with salvage radiotherapy. Apart from pre-op and serial post-op PSA levels, number of positive margins based on anatomical classification of prostate, lymphovascular and perineural invasion, Gleason score and T-stage of the cancer were documented accurately. Results: Fifty one patients (66.2\%) had a single positive margin, while 26 (33.8\%) had multiple positive margins. Among all 77 patients, 67 (87\%) had biochemical failure. Cox regression analysis showed that among various parameters, only pre-op PSA $>20 \mathrm{ng} / \mathrm{ml}$ and having more than one positive margins were able to predict the likelihood of biochemical failure in the patients; while Gleason score, perineural invasion and lymphovascular invasion did not seem to have an important role in this regard.

Conclusions: Among patients with positive surgical margins after radical prostatectomy, those with pre-op PSA $>20 \mathrm{ng} / \mathrm{ml}$ or more than one positive margins are at greater risk of biochemical or/and clinical failure. In these patients, starting salvage radiotherapy after surgery might be considered as a logic option.
\end{abstract}

\section{Background}

In most developed countries, prostate adenocarcinoma is the most common malignancy amongst men, and the second most frequent cause of cancer-related death (1). Radical prostatectomy is an established treatment modality for prostate cancer, especially in early stage disease. Although following radical prostatectomy many patients would suffer from biochemical, local, or distant failure, it is still difficult to predict which patients will eventually develop such failures. To do so, several prognostic indicators including margin involvement have been identified (2). Even with the most accurate pre-operative staging as well as surgical techniques,

it has been estimated that $12-43 \%$ of those undergoing radical prostatectomy are found to have positive surgical margins, although recent studies have reported a lower rate of margin involvement (2-7).

Pathologists define a positive surgical margin as "the presence of tumor at the inked surface of the resected specimen", which indicates incomplete excision of malignant tissue $(3,4)$.

Many studies have shown that a positive surgical margin represents an independent predictor of biochemical recurrence after radical prostatectomy. On the other hand, several other studies have demonstrated that 
many men with positive surgical margins do not develop biochemical recurrence (8-10). As patients with positive surgical margins show an unpredictable clinical course, their proper management still remains controversial.

\section{Objectives}

The aim of this study was to assess the factors that might predict the higher risk of disease recurrence in prostate cancer patients with positive surgical margins.

\section{Patients and Methods}

In this prospective cohort study which was done at Labbafinejad Hospital in Tehran from March 2009 till Oct 2013, seventy seven patients who had pathologically proven positive surgical margins after radical prostatectomy were followed and serum PSA levels were measured every three months. In case of any increase, the levels were checked in shorter intervals and in case of more than $0.2 \mathrm{ng} / \mathrm{mL}$ increase in two or more measurements, patients were classified as having "biochemical failure" and were treated with salvage radiotherapy. Apart from pre-op and serial post-op PSA levels, number of positive margins based on anatomical classification of prostate, lymphovascular and perineural invasion, Gleason score and T-stage of the cancer were documented accurately. Biochemical failure free survival from the time of surgery was determined by Kaplan-Meier method. Multivariate analysis was performed using Cox Proportional Regression and data were analyzed using SPSS software. P-values less than 0.05 were considered significant.

\section{Results}

Mean age of the patients was $67.1 \pm 5.6$ years. Median
Gleason score was 7, and mean pre-op PSA level was 15.8 $\pm 11.1 \mathrm{ng} / \mathrm{dL}$. Perineural and lymphovascular invasions were seen in $68(88.3 \%)$ and $28(36.4 \%)$ of the patients respectively. $22.1 \%$ of patients had low risk (T2a and T2b) disease, while $77.9 \%$ had intermediate or high risk (T2c, T3a or T3b) disease. Fifty one patients $(66.2 \%)$ had a single positive margin, while 26 (33.8\%) had multiple positive margins (Table 1).

Among all 77 patients, 67 (87\%) had biochemical failure. In this group, median and mean biochemical failure free survivals were 16 and 25.1 months, respectively. Cox regression analysis showed that among various parameters, only pre-op PSA and number of positive margins were able to predict the likelihood of biochemical failure in the patients while Gleason score, perineural invasion and lymphovascular invasion did not differ significantly between the patients with and without failure (Table 2).

Table 1. Site of Positive Margins

\begin{tabular}{lc}
\hline Site of Positive Margin & Patients $^{\text {a }}$ \\
\hline Apical & $39(50.6)$ \\
\hline Apical + lateral & $4(5.2)$ \\
\hline Apical + bladder neck & $7(9.1)$ \\
\hline Lateral & $4(5.2)$ \\
\hline Lateral + bladder neck & $15(19.5)$ \\
\hline Bladder neck & $8(10.4)$ \\
\hline
\end{tabular}

a Data are presented as No. (\%).

Table 2. Studied Parameters

\begin{tabular}{lccc}
\hline Parameter & Description & Odd Ratio & P Value \\
\hline Gleason score & $\leq 7$ or $>8$ & 0.92 & 0.7 \\
Pre-op PSA, ng/dL & $\leq 20$, or $>20$ & 0.51 & 0.03 \\
\hline Perineural invasion & Yes/No & 1 & 0.9 \\
lymphovascular invasion & Yes/No & 0.63 & 0.89 \\
\hline Number of positive margins & One/More than one & 5.8 & 0.02 \\
\hline Stage & Low risk or high risk & 0.7 & 0.15 \\
\hline
\end{tabular}




\section{Discussion}

Several prognostic factors including margin involvement have been proposed to be able to predict the local and/or biochemical recurrence following radical prostatectomy (2).

As noted above, a positive surgical margin means incomplete excision of malignant tissue $(3,4)$. Sites designated with margin status include: the apex (including urethral limit), the base (including bladder neck margin), the vasal and the circumferential - anterior, lateral, rectal or posterior surface $(3,11,12)$. Patients are at significant risk of biochemical and subsequent clinical relapse, although not all patients will suffer disease recurrence. A study from Johns Hopkins Hospital reported that 55\% of men positive margins were progression-free over a 10year period, while this figure was $79 \%$ in men with negative margins (13).

Many experts-based on several studies- consider a positive surgical margin as an independent predictor of biochemical failure after radical prostatectomy.

By contrast, many studies have shown that quite a lot of men with positive surgical margins never develop biochemical relapse (8-10).

These contradictory data make the management of these individuals challenging and in many cases the treatment decision is made on an individual basis. In this regard, finding other factors that might have an effect in the clinical course of such patients in order to predict the probability of relapse seems essential.

Our study showed that the risk of biochemical failure in patients with positive surgical margins following radical prostatectomy could be as high as $87 \%$. Our figure is much higher than that of many other studies. For instance, in Simon et al study (14) only 19\% patients with positive margins developed biochemical failure, compared to $7 \%$ of margin negative individuals. The reason of this significant difference remains elusive. Furthermore, our results showed that Gleason score, perineural invasion and lymphovascular invasion were not significantly different between the patients with and without failure. This is in contrast with the results of some other studies, such as Shikanov study (15) which showed that Gleason score and lymphovascular invasion as well as number of positive margins were important predictive factors for biochemical failure after radical prostatectomy.

Grossfeld et al. in their study on 1383 patients found that compared to patients with negative margins, those with positive surgical margins were significantly more likely to undergo secondary adjuvant or neoadjuvant cancer treatment, and had significantly higher rates of biochemical failure.

In sub-analysis after adjusting for age, ethnicity, PSA at diagnosis, pathological stage and Gleason score, they demonstrated that while the number of positive margins and positive margin location had little impact on the outcomes measured, surgical margin status was still an important independent predictor of PSA recurrence and secondary treatment (16).

In contrast, some studies have found controversial results. For instance, another study from Johns Hopkins Hospital showed that in patients with Gleason score less than 7, positive surgical margins had no impact on 10-year probability of biochemical recurrence, while those with Gleason score of 7 or more did significantly worse (17).

Stamey et al also showed that while the percentage of Gleason grade 4 or 5, cancer volume, presence of positive lymph nodes, and intraprostatic vascular invasion were independently associated with disease progression and relapse after radical prostatectomy, margin status was not an independent predictor of failure when adjusting for Gleason score, tumor volume and lymph node status (18).

Savdie et al. (19) in their study on 940 patients assessed the importance of the grade of the tumor cells that were present at the surgical margin. They found that the patients who had high grade tumor (Gleason score 4 or 5) at the site of positive surgical margin, compared to the ones with lower grade tumoral cells, were more likely to suffer from disease recurrence.

They concluded that the grade of tumoral cells at the surgical margin can be considered as an independent predictor of biochemical recurrence after radical prostatectomy. In their study, patients with lower grade carcinoma at the margin had a similar prognosis to the ones with negative margins.

In a large study on 11521 patients, the authors concluded that although a positive surgical margin can increase the risk of biochemical failure and need for secondary therapy, it does not appear to affect the risk of cancer-related mortality within 10 - 15 years of radical prostatectomy (4). Some studies have shown that in case of seminal vesicle or lymph node involvement, margin status may not be independently predictive due to the overwhelming risk of disease recurrence associated with those two factors $(20,21)$. There is evidence that factors such as the location, extent and number of positive margins may have an impact on disease recurrence $(13,22)$.

Study of Blute et al. (11) demonstrated that the site of positive margins was a significant predictor of progression. Their study showed that compared with patients with negative margins, patients with pT2No disease with a single margin involvement at either the apex/urethra or anterior/posterior prostate or multiple positive margins in these sites; had only marginally reduced PSA-free rates at 5 years ( 79,78 and $82 \%$ compared with $86 \%$ ).

In contrast, patients who had a positive surgical margin in the prostate base had significantly higher biochemical or clinical failure rates at 5 years.

In this study, after matching for Gleason score, pre-operative PSA and DNA ploidy, the risk of PSA progression was 1.68 times higher in men with positive margins.

There seems to be a difference between a focal compared with an extensive positive margin. Various studies have reported that extensive positive margins were associated 
with higher rate of relapse compared with focal positive margins. Therefore, apart from site of involvement, number and extent of positive surgical margins also can provide valuable prognostic information $(3,13,23,24)$.

The question still remains that why a positive margin is not always associated with tumor recurrence? Some experts believe that ischemia and fibrosis caused by surgery may destroy small areas of residual carcinoma. Another explanation is that extraprostatic prostate cancer cells are probably more adherent to the prostate than the surrounding adipose tissue. As a result, when the prostate is lifted away from the surrounding tissue the malignant cells adhere to the specimen; positive margin might be a false one due to inadvertent damage caused while preparing the specimen for histological examination $(3,25,26)$.

Identifying that subset of patients who are at a greater risk of recurrence seems essential, as this group can be offered further therapies such as radiotherapy. There is evidence that prostate cancer patients with localized disease but positive margins can have a survival benefit if recieve adjuvant radiation therapy (27). Some evidence exist that neoadjuvant androgen deprivation can decrease the incidence of positive margins, however, this approach has not yet been shown to affect disease-free survival (28). With the inadequacies of current staging and surgical techniques, the occurrence of positive surgical margins seems inevitable. Large trials are needed to further clarify the role of various salvage therapies in the management of patients with positive surgical margins following radical prostatectomy.

\subsection{Conclusion}

Our study showed that patients with positive surgical margins following radical prostatectomy in whom there were more than one pathologically proven positive surgical margin, or in whom peo-op PSA level was more than $20 \mathrm{ng} / \mathrm{dL}$, have an increased risk of biochemical failure. In these patients, starting salvage radiotherapy after surgery (before development of biochemical failure) might be considered as a logic option. However, impact of this approach on overall survival is not known.

\section{References}

1. Siegel R, Naishadham D, Jemal A. Cancer statistics, 2013. CA CancerJClin. 2013;63(1):11-30.

2. Emerson RE, Koch MO, Jones TD, Daggy JK, Juliar BE, Cheng L. The influence of extent of surgical margin positivity on prostate specific antigen recurrence. J Clin Pathol. 2005;58(10):1028-32.

3. Bott SR, Kirby RS. Avoidance and management of positive surgical margins before, during and after radical prostatectomy. Prostate Cancer Prostatic Dis. 2002;5(4):252-63.

4. Stephenson AJ, Eggener SE, Hernandez AV, Klein EA, Kattan MW, Wood DJ, et al. Do margins matter? The influence of positive surgical margins on prostate cancer-specific mortality. EurUrol.2014;65(4):675-80.

5. Wieder JA, Soloway MS. Incidence, Etiology, Location, Prevention and Treatment of Positive Surgical Margins after Radical Prostatectomy for Prostate Cancer. J Urol. 1998;160(2):299-315.

6. Cheng L, Slezak J, Bergstralh EJ, Myers RP, Zincke H, Bostwick DG. Preoperative prediction of surgical margin status in patient with prostate cancer treated by radical prostatectomy.J Clin Oncol. 2000;18(15):2862-8.

7. Eichelberger LE, Koch MO, Daggy JK, Ulbright TM, Eble JN, Cheng L Predicting tumorvolume in radical prostatectomy specimens from patients with prostate cancer. Am J Clin Pathol. 2003;120(3):386-91.

8. Godoy G, Tareen BU, Lepor H. Site of positive surgical margins influences biochemical recurrence after radical prostatectomy. BJU Int 2009;104(11):1610-4.

9. Karakiewicz PI, Eastham JA, Graefen M, Cagiannos I, Stricker PD, Klein E, et al. Prognostic impact of positive surgical margins in surgically treated prostate cancer: multi-institutional assessment of 5831 patients. Urology. 2005;66(6):1245-50.

10. Wright JL, Dalkin BL, True LD, Ellis WJ, Stanford JL, Lange PH, et al Positive surgical margins at radical prostatectomy predict prostate cancer specific mortality.J Urol. 2010;183(6):2213-8.

11. Blute ML, Bostwick DG, Bergstralh EJ, Slezak JM, Martin SK, Amling $\mathrm{CL}$, et al. Anatomic site-specific positive margins in organ-confined prostate cancer and its impact on outcome after radical prostatectomy. Urology. 1997;50(5):733-9.

12. Silberstein JL, Eastham JA. Significance and management of positive surgical margins at the time of radical prostatectomy. Indian J Urol. 2014;30(4):423-8.

13. Cao D, Humphrey PA, Gao F, Tao Y, Kibel AS. Ability of linear length of positive margin in radical prostatectomy specimens to predict biochemical recurrence. Urology. 2011;77(6):1409-14.

14. Simon MA, Kim S, Soloway MS. Prostate specific antigen recurrence rates are low after radical retropubic prostatectomy and positive margins.J Urol. 2006;175(1):140-4.

15. Shikanov S, Song J, Royce C, Al-Ahmadie H, Zorn K, Steinberg G, et al. Length of positive surgical margin after radical prostatectomy as a predictor of biochemical recurrence. JUrol. 2009;182(1):139-44.

16. Grossfeld GD, Chang JJ, Broering JM, Miller DP, Yu J, Flanders SC, et al. Impact of positive surgical margins on prostate cancer recurrence and the use of secondary cancer treatment: data from the CaPSURE database. J Urol. 2000;163(4):1171-7.

17. Lowe BA, Lieberman SF. Disease recurrence and progression in untreated pathologic stage T3 prostate cancer: selecting the patient for adjuvant therapy.JUrol. 1997;158(4):1452-6.

18. Stamey TA, McNeal JE, Yemoto CM, Sigal BM, Johnstone IM. Biological determinants of cancer progression in men with prostate cancer. JAMA. 1999;281(15):1395-400.

19. Savdie R, Horvath LG, Benito RP, Rasiah KK, Haynes AM, Chatfield M, et al. High Gleason grade carcinoma at a positive surgical margin predicts biochemical failure after radical prostatectomy and may guide adjuvant radiotherapy. BJU Int. 2012;109(12):1794-800.

20. Swanson GP, Basler JW. Prognostic factors for failure after prostatectomy.J Cancer. 2011;2:1.

21. Cao D, Kibel AS, Gao F, Tao Y, Humphrey PA. The Gleason score of tumor at the margin in radical prostatectomy is predictive of biochemical recurrence. Am J Surg Pathol. 2010;34(7):994-1001.

22. Grossfeld GD, Tigrani VS, Nudell D, Roach M, Weinberg VK, Presti JC et al. Management of a Positive Surgical Margin after Radical Prostatectomy: Decision Analysis. J Urol. 2000;164:93-100.

23. Blute ML, Bostwick DG, Seay TM, Martin SK, Slezak JM, Bergstralh EJ, et al. Pathologic classification of prostate carcinoma. Cancer. 1998;82(5):902-8.

24. Epstein JI, Pizov G, Walsh PC. Correlation of pathologic findings with progression after radical retropubic prostatectomy. Cancer. 1993;71(11):3582-93.

25. Yossepowitch O, Briganti A, Eastham JA, Epstein J, Graefen M, Montironi R, et al. Positive surgical margins after radical prostatectomy: a systematic review and contemporary update. Eur Urol. 2014;65(2):303-13.

26. Furubayashi N, Negishi T, Hirata Y, Taguchi K, Shimokawa M, Nakamura M. Positive resection margins may not reflect the true margin in patients undergoing radical prostatectomy. Oncol Lett. 2014;8(5):2237-42.

27. Dillman RO, Hafer R, Cox C, McClure SE. Overall survival benefit from postoperative radiation therapy for organ-confined, marginpositive prostate cancer. Int J Radiat Oncol Biol Phys. 2011;79(3):719-23.

28. Gomella LG, Singh J, Lallas C, Trabulsi EJ. Hormone therapy in the management of prostate cancer: evidence-based approaches. Ther Adv Urol. 2010;2(4):171-81. 